\title{
Narrative change in emotion-focused psychotherapy: A study on the evolution of reflection and protest innovative moments
}

\author{
INÊS MENDES ${ }^{1}$, ANTÓNIO P. RIBEIRO ${ }^{1}$, LYNNE ANGUS ${ }^{2}$, LESLIE S. GREENBERG $^{2}$, \\ INÊS SOUSA, ${ }^{3} \&$ MIGUEL M. GONÇALVES ${ }^{1}$ \\ ${ }^{1}$ School of Psychology, University of Minho, Portugal; ${ }^{2}$ Department of Psychology, York University, North York, Ontario, \\ Canada $\mathcal{F}^{3}$ Department of Mathematics for Science and Technology, University of Minho, Portugal
}

(Received 18 August 2010; revised 16 February 2011; accepted 16 February 2011)

\begin{abstract}
Innovative moments (IMs) are exceptions to a client's problematic self-narrative in the therapeutic dialogue. The innovative moments coding system is a tool which tracks five different types of IMs - action, reflection, protest, reconceptualization and performing change. An in-depth qualitative analysis of six therapeutic cases of emotion-focused therapy (EFT) investigated the role of two of the most common IMs - reflection and protest - in both good and poor outcome cases. Through this analysis two subtypes (I and II) of reflection and protest IMs were identified, revealing different evolution patterns. Subtype II of both reflection and protest IMs is significantly higher in the good outcome group, while subtype I of both IMs types does not present statistically significant differences between groups. The evolution from subtype I to subtype II across the therapeutic process seems to reflect a relevant developmental progression in the change process.
\end{abstract}

Keywords: process research; narrative; emotion-focused therapy; innovative moments

According to a narrative framework, individuals are storytellers, forging their identities through the stories they tell about themselves, others and the world (Angus \& McLeod, 2004; Bruner, 1986; McAdams, 1993; Polkinghorne, 1988; Sarbin, 1986; White \& Epston, 1990). The transformation of a problematic self-narrative - construed as a set of rules of acting, feeling and thinking which are maladaptive (Gonçalves, Ribeiro, Mendes, Matos, \& Santos, in press) - is made possible by the integration of new events in clients' self-narratives and also by the revaluation of the former ones. Either way, novelties emerge, understood as different ways of acting, thinking or feeling, which we call innovative moments (IMs) (Gonçalves, Matos, \& Santos, 2009; Gonçalves, Santos, et al., 2010). IMs entail a significant difference from the problematic selfnarrative which is being experienced by the clients. For instance, if a problematic self-narrative could be characterized by the rule "always be kind to others and ignore your own wishes" then we might expect several effects from this in client's life: lack of assertiveness, difficulty in expressing one's own feelings, low self-esteem, and so on. All the exceptions to this rule, such as expressing one's needs and rights, or valuing own ideas, or feeling good with oneself, would be identified as IMs. Thus, IMs represent new pathways of thinking, feeling and acting in peoples' lives that, when expanded, could lead to the construction of a new self-narrative (that is, new ways of action, feeling, thinking, and relating). The notion of IMs was inspired by the concept of unique outcome from the narrative model of White and Epston (1990), being an empirical operationalization for this notion.

Recent studies (quantitative and qualitative) have shown that change in psychotherapy can be described by the emergence of IMs (Gonçalves, Mendes, Cruz, et al., 2011; Gonçalves, Mendes, Ribeiro, Angus, \& Greenberg, 2010; Matos, Santos, Gonçalves, \& Martins, 2009; Mendes et al., 2010; Santos, Gonçalves, \& Matos, 2010; Santos, Gonçalves, Matos, \& Salvatore, 2009; Ribeiro, Gonçalves, \& Ribeiro, 2009). These studies have been using the innovative moments coding system (IMCS) (Gonçalves et al., in press) to track five different types of IMs in therapeutic conversation.

Correspondence concerning this article should be addressed to Miguel M. Gonçalves, School of Psychology, University of Minho, 4710 Braga, Portugal. Email: mgoncalves@psi.uminho.pt 
1. Action IMs are new accomplishments, specific actions which are different from those that the problem impels the client to undertake.

2. Reflection IMs refer to new ways of thinking and new understandings about the implications of the problem in the client's life which allow him or her to defy the constraints of the problematic story.

3. Protest IMs entail new behaviors (like action IMs) and/or thoughts (like reflection IMs) against the problem, representing a refusal of its assumptions. It is this active refusal that allows one to distinguish protest from action and reflection IMs.

4. Reconceptualization IMs are a more complex and multifaceted type of IM which enables the client's comprehension about what is different in him or herself and the process that fostered this transformation. These IMs require the elaboration of two components: A contrast between the self in the past (problematic selfnarrative) and the self in the present (the emergent new self-narrative) and the depiction of the process that allowed for this change to occur.

5. Performing change IMs represent the performance of change, new ways of acting and being which are the consequence of the change process. They represent an extension into the future of the changes produced so far.

Several studies with samples and single cases using this methodological tool were developed to analyze psychotherapy change, corroborating its applicability to diverse therapeutic modalities. Hypothesis-testing studies in narrative therapy (NT) (Matos et al., 2009), emotion-focused therapy (EFT) (Mendes et al., 2010) and client-centered therapy (CCT) (Gonçalves, Mendes, Cruz, et al., 2011) and also single-case studies in constructivist therapy focused on implicative dilemmas (Ribeiro et al., 2009) and constructive therapy with complicated grief (Alves, Mendes, Neimeyer, \& Gonçalves, 2011) have shown that IMs reveal a significantly higher presence in good outcome than in poor outcome cases. This difference between good and poor outcome cases is mainly due to the differences in two types of IMs: reconceptualization and performing change. Thus, action, reflection and protest IMs have a similar magnitude in poor and good outcome cases, contrarily to reconceptualization and performing change IMs. Moreover reconceptualization and performing change IMs, in good outcome cases, display an increasing trend from mid therapy until termination, and at the end of therapy reconceptualization IMs are often the most dominant type of innovation. Reconceptualization and performing change IMs are usually absent or have a much reduced expression in poor outcome cases. These two types seem to be vital for therapeutic change. From these studies with IMCS a heuristic model of change in successful brief therapy was developed (Gonçalves et al., 2009; Matos et al., 2009). Here, we present a summary of this model. In the first stage of therapy, action and reflection IMs are the first ones to appear and they constitute the first signs that something new is emerging in the client's life, representing new ways of acting and new understandings. Protest IMs appear after the first cycles of action and reflection IMs or, in other cases, they emerge alongside action and reflection IMs early on in therapy. Such IMs embody a refusal of the assumptions of the problematic self-narrative, representing a strong attitudinal movement against the problem which has been dominating the client's life. This movement of refusal of the problematic selfnarrative enables the repositioning of the self in a more proactive and agentic stance in therapy and in life. Action, reflection and protest, although representing meaningful novelties in the client's life, seem to be insufficient for a sustainable change to emerge. Reconceptualization is crucial for the construction of a new self-narrative. Such IMs typically emerge in the middle stage of therapy after several sequences of action, reflection and protest IMs. Reconceptualization involves two central ingredients for the change process. First it entails a contrast between a past problematic self-narrative and a new emergent one (e.g., "before I was doing everything I could to be accepted by others, now I'm more confident with myself"). We suggested that this contrast grants narrative coherence to the more episodic action, reflection and protest IMs, also allowing for a sense of continuity to be achieved. Without this contrast we would have a "jump" between the problematic self-narrative and the emerging new one. Second, the person has some knowledge of how this transition between the past and present narratives was achieved. Hence, we argued that this IM entails a meta-position through which the client has access to the change process from the past problematic self-narrative to the new emerging one (e.g., "dealing with some of the hurts, bringing them out here and putting them where they belong, allowed this change to occur") (see also Hermans, 2003). Therefore, reconceptualization IMs imply a metacognitive integration of the past problematic self-narrative, the present emerging one and the processes that enable this transformation. In successful therapy, the integration of these positions allows the client to advance the new emerging self-narrative, compromising him or 
herself with the changes that were occurring. Congruently with this importance of reconceptualization IMs, several researchers have emphasized the centrality of developing metacognitive skills in the therapeutic change (see Semerari et al., 2003; Semerari, Carcione, Dimaggio, Nicolò, \& Procacci, 2007).

After some elaboration of reconceptualization IMs, new cycles of novelties exploration occur, again in the form of action, reflection and protest IMs that are congruent with the previous reconceptualization IMs. In turn, these occurrences further validate reconceptualization IMs: as clients narrate themselves differently than before (reconceptualization IMs), new actions, thoughts and feelings, congruent with the content of the reconceptualization IMs, further support the narrated changes. Performing change IMs are projections into the future of this new position which allows for the new self-narrative to have a future (see Figure 1).

Research regarding IMs in clinical samples (NT; Matos et al., 2009; EFT; Mendes et al., 2010; CCT; Gonçalves, Mendes, Cruz, et al., 2011) has focused on the differences among groups, highlighting the role of reconceptualization and performing change IMs in the construction of psychotherapeutic change. These studies have overlooked the role of action, reflection and protest IMs in the process of change since they do not reveal significant differences among outcome groups. However, although action IMs are in some samples relatively rare, as in EFT (Mendes et al., 2010), reflection and protest are very common in the modalities of therapy studied so far (Gonçalves, Santos, et al., 2010; Matos et al., 2009) and they precede the elaboration of reconceptualization in good outcome cases. Moreover, they are the most common IMs all along the therapeutic process in poor outcome cases and the most common in the initial and middle phases of therapy in good outcome cases.
In this study we intend precisely to shed some light on the role of these IMs in the change process. Thus, the main target of this research is to study how reflection and protest IMs evolve in good and poor psychotherapy outcomes, trying to understand how they might contribute to the process of change. One way to research this problem is to study whether, despite the absence of differences between good and poor outcome cases on reflection and protest IMs at a quantitative level, there are any differences at a more qualitative, fine-grained level. That is, are there different kinds of these IMs that emerge differently in good and in poor outcome cases?

\section{Reflection and Protest IMs}

In a previous single-case study with the IMCS (Gonçalves, Mendes, Ribeiro, et al., 2010) in the well-known and intensively studied case of Lisa (Angus, Goldman, \& Mergenthaler, 2008; Brinegar, Salvi, \& Stiles, 2008; Carcione et al., 2008; Greenberg, 2008; Honos-Webb, Stiles, Greenberg \& Goldman, 1998; Lepper \& Mergenthaler, 2008; Nicolò et al., 2008), two different types of reflection and protest IMs emerged throughout the therapeutic process. We depart from what we have found in this case to test whether the same applies in other cases of EFT. In this case, reflection IMs evolves throughout therapy from (1) new understandings about the problem and its causes to (2) new strategies to deal with the problem and new views of the self. We termed the former type of reflection subtype I and the later subtype II, highlighting that these subtypes clearly involve different meanings, pointing to different processes of change.

A similar differentiation and evolution was visible on protest IMs: Lisa evolves from a problemoriented position (protest subtype I), in which she is focused on criticizing the problem (or the others that might support it); to the emergence of new views of the self, in which she asserts her rights and

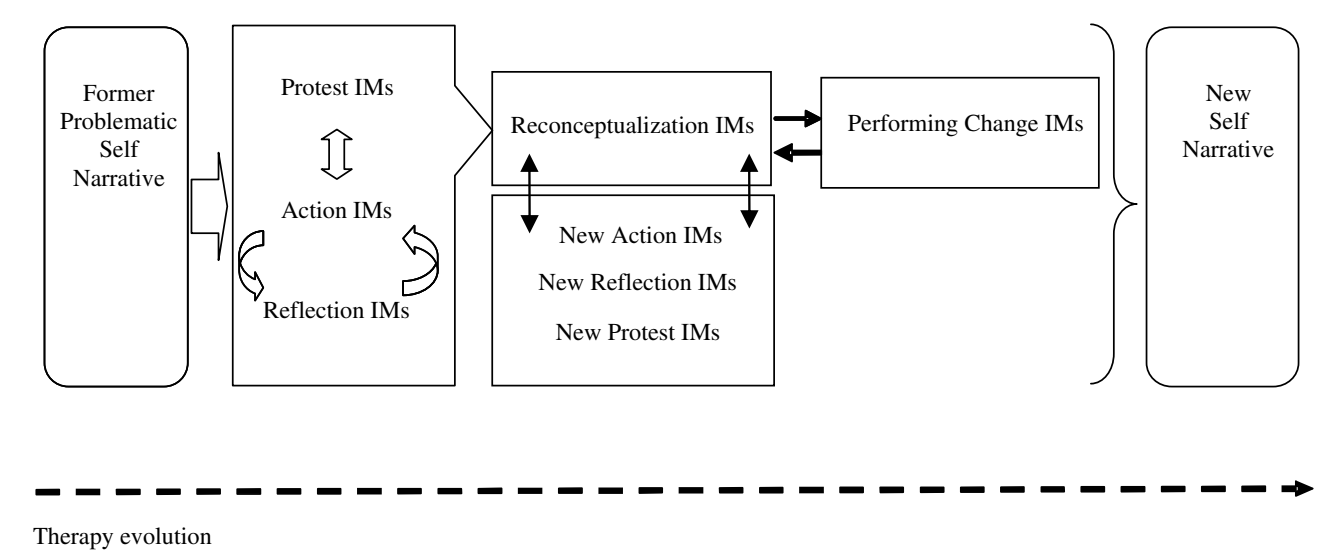

Figure 1. Heuristic model of good outcome cases. 
wishes (protest subtype II) (Gonçalves, Mendes, Ribeiro, et al., 2010). To further illustrate these differences we present the subtypes-I and II-of both reflection and protest IMs followed by a clinical vignette from Lisa's case (Gonçalves, Mendes, Ribeiro, et al., 2010), depression being the problematic background.

\section{Reflection IM Subtype I-Creating Distance from the Problem}

This IM subtype involves new formulations and comprehensions about the problem, new understandings about the problem's causes and effects on the client's life and intentions to defy it.

\section{Clinical Vignette}

Therapist: So it's sort of-like you don't-you don't really trust him (husband) anymore?

Client: I don't, I have no trust for him, this is why maybe I've come to a point where I have said okay, I'm not going to continue banging my head against the wall, it's tiring and it's so much; you know-I consume my energy. (...) and it just feels like I have to do something now

Therapist: So it's getting ... it's just feeling pretty bad right now, is what you're saying right?

Client: It's like I don't want to go another day without doing something (crying). (Fourth session-new comprehension about the problem)

\section{Reflection IM Subtype II-Centered on Change}

This subtype considers Lisa's elaboration about the therapeutic process, the strategies that she implemented in order to achieve therapeutic goals towards change, statements of the difference between a past and a present view of the self and feelings of wellbeing that come along with the awareness of these changes.

\section{Clinical Vignette}

Client: (crying) I want to um grow and um, experience what I have to offer and um, um, just to learn about what's out there.

Therapist: Mm-hm. What's happening when you say that?

Client: Yeah, I'm positive about it. (...) I feel positive and strong.
Therapist: $\mathrm{Mm}-\mathrm{hm}$.

Client: It's okay to ask for these things [acceptance for who she is and what she feels].

Therapist: You feel okay about it?

Client: Yeah, yeah, it's a-it's a part of me, so I'm not going to um, turn it down. (Twelfth sessionelaborating about her change process)

\section{Protest IM Subtype I-Problem-Oriented Positions}

Protest subtype I enables the self-disclosure of the negative affect that the problem brought into the client's life. This subtype entails a confrontational position in which Lisa criticizes the problem's assumptions and the people who may be supporting them. The client's discourse is centered on others and focuses on criticizing the ones she feels hurt or neglected by.

\section{Clinical Vignette}

(during an empty-chair dialogue with the client's father assuming a position of critique)

Client: Yeah, I resented pretend living that way, it really makes me angry.

Therapist: Tell him about that anger. It really makes you angry.

Client: Um, it wasn't fair to be brought up that way. I think you're very selfish!

Therapist: Say that again.

Client: I think you're very selfish!

Therapist: What do, what do you feel as you say that, there's some real power in that, the way that you say that.

Client: Just thought about yourself, and you only took the good things and not the bad, um - uh, only thought about yourself and not me or my brothers or mom.

Therapist: So was it like, I want you, I wanted you to think about me.

Client: Yes, and you only thought about me when you thought it was important to you and only what, what you wanted at that time. (Third session) 


\section{Protest IM Subtype II-Emergence of Self- Empowerment}

This corresponds to a position of assertiveness in which the client repositions herself in relation to the problem. Lisa assumes a different stand centering the discourse on the self and on the self-assertion of her needs, enabling her to feel that she does matter and that caring about oneself is an important priority. This creates a feeling of entitlement of one's own needs and rights building a sense of personal agency that will foster positions of selfempowerment and strength.

\section{Clinical Vignette}

Therapist: Mm-hm. So what do you feel towards him right now?

Client: I feel bigger and-and taller and-I feel that I can — stand up for myself.

Therapist: Mm-hm - what happens when you say that-I feel I can stand up for myself-you can just - get up and - walk out - tell, wanted to

Client: Because um I'm an adult and-I can make my own decisions... I deserve to feel what I feel and - ah what I - want to do and is right for me and my kids - I'm going to stand up for myselfum-I deserve that - I'm a good person and I'm not going to let you step on me anymore. (Fifth session - empty-chair dialogue with client's husband-self-empowerment).

This differentiation between types suggests that subtype I - in both reflection and protest IMs - is clearly less developed than subtype II, in terms of the therapeutic change progress. Notice that in reflection IMs it is the difference between the comprehension of the problem and the reflection about change which allows differentiating subtypes. The differentiation of protest subtype I and II also reflects very different processes. In the first, Lisa is rejecting the problem or its assumptions, mainly centering herself on others; in the subtype II she is centering on her needs.

As the model of change previously presented suggests, reflection and protest IMs are signs that change is taking place, to the client and to significant others. Consequently, these IMs are most likely to be the precursors of reconceptualization in good outcome cases. In contrast, in poor outcome cases it seems that clients are unable to construct other types of novelties besides these ones. Somehow they are stuck in reflection and protest IMs (sometimes also in action IMs), without being able to construct reconceptualization and performing change IMs. Thus, studying how reflection and protest IMs evolve and how their subtypes develop in good and poor outcome cases will certainly add a refinement to the model of change previously presented.

Hence, we formulate the following research questions for the present study:

1. As in Lisa's case, are reflections and protest IMs' subtypes present and reliably identified in the other EFT cases?

2. Are reflection and protest subtype II more typical of good outcome cases in EFT?

3. What is the evolution of these subtypes throughout therapy, in good and poor outcome cases of EFT?

\section{Method}

\section{Clients}

Clients were part of the York I Depression Study (Greenberg \& Watson, 1998), a project designed to assess treatments of major depression comparing 17 process-experiential (PE; also referred as EFT) and 17 client-centered therapy (CCT) cases. In this study the clients were randomly assigned to one of the two different treatments (EFT or CCT). We studied six out of 17 cases assigned to EFT, in which the subjects had 15 to 20 sessions of individual psychotherapy once a week. These six cases were the ones with complete transcripts and data sets for intensive process analyses.

Of the six clients in this sample, four were women and two were men (age range $=27-63$ years, $M=$ 45.50 years, $S D=13.78)$. Clients completed an average of $17.50(S D=1.87)$ sessions. Five of the clients were married and one was divorced. All the clients were Caucasian.

Clients were classified as having good or poor outcomes based upon the analysis of the Beck Depression Inventory (BDI) (Beck, Steer, \& Garbin, 1988; Beck, Ward, Mendelson, Mock, \& Erbaugh, 1961) pre- to post-test change scores. BDI is a wellknown 21 item self-report instrument to assess symptoms of depression.

A Reliable Change Index (RCI) analysis of BDI pre- to post-test change scores classified three clients as having met the criteria for recovery (i.e., passed both a BDI cut-off score of 11.08 and RCI criteria) and the other three clients were classified as unchanged (i.e., have not passed both BDI cut-off score of 11.08 and RCI criteria) at treatment termination (see Jacobson \& Truax, 1991; McGlinchey, Atkins, \& Jacobson, 2002) (see Table I). 
Table I. Pre- to post-BDI scores

\begin{tabular}{lcc}
\hline & Pre-BDI & Post-BDI \\
\hline Case 1 & 25 & 3 \\
Case 2 & 30 & 5 \\
Case 3 & 35 & 4 \\
Case 4 & 15 & 13 \\
Case 5 & 23 & 22 \\
Case 6 & 24 & 18 \\
\hline
\end{tabular}

Note: Case 1, 2 and 3 belong to the good outcome group and cases 4,5 and 6 constitute the poor outcome group.

\section{Therapists}

Five therapists conducted the therapeutic process of the six clients analyzed in this study. Four of the therapists were female and one was male. They were of varied levels of education, from advanced doctoral students in clinical psychology to $\mathrm{PhD}$ clinical psychologists. Four of the therapists were of Caucasian origin and one was Indian. All therapists received 24 weeks training according to the manual devised for the York I Depression Study (Greenberg, Rice \& Elliott, 1993). The training consisted of eight weeks of CCT, six weeks for systematic evocative unfolding, six weeks for two-chair dialogue and four weeks for empty-chair dialogue. Data regarding the therapists' adherence to the manual, as well other relevant data, can be found in Greenberg and Watson's (1998) article on this sample. The therapeutic alliance was assessed with the working alliance inventory (WAI) (Horvath \& Greenberg, 1989) and high values were reported in both outcome groups.

\section{Treatment}

Therapeutic relationship is one of the core principles of EFT which implies the facilitation by the therapist of a relationship based on attunement, validation, empathy and trustworthiness, providing a safe and responsive therapeutic environment. Generally, the goal in EFT is to promote emotional awareness and enhance clients' emotional processing. Two-chair dialogue for self-evaluative and self-interruptive conflict splits, empty-chair dialogue for unfinished business with a significant other, focusing (Gendlin, 1981) at a marker of an unclear felt sense and systematic evocative unfolding for problematic reactions, are the therapeutic interventions added to the client-centered relational conditions in EFT. The therapists on the York I Depression Study followed the manual developed by Greenberg, Rice and Elliott (1993).

\section{Procedure}

IM coding and reliability. In a previous study, six EFT cases, from the York I Project on Depression Study (Greenberg \& Watson, 1998), were coded according to the IMCS (Mendes et al., 2010). We summarize here the procedures used in that study on IMs' coding. Two coders were intensively trained on this methodological tool until they reached reliability (Cohen's Kappa higher than .75). After the IMs training, the two coders, who were unaware of the outcome status of the cases, consensually defined the problem in order to be able to track the IMs, the type and the definition of each IM's salience. To measure salience when we use transcripts, as in this study, we use a textual salience index (percentage of words of the session involved in the IM's elaboration). The sessions were coded from the transcripts of the cases

The percentage of agreement on the overall IMs' salience was of .89. Reliability of distinguishing the IM's type, assessed by Cohen's Kappa, was of .86 (based upon a sample of 1397 IMs).

\section{Reflection and protest IM subtypes coding.} For the present study, we developed an in-depth analysis of the speech content of reflection and protest IMs from all the sessions $(n=105)$ of the six therapeutic cases in order to understand whether reflection and protest IMs can be reliably distinguished into subtype I and subtype II, as was done in Lisa's case (Gonçalves, Mendes, Ribeiro, et al., 2010). The data from the two outcome groups - three good and three poor outcome cases-were intensively analyzed. Hence, 49 sessions fit into the good outcome group and 56 sessions compose the poor outcome data set.

Therefore, 105 therapeutic sessions were reviewed in which 775 reflection IMs and 377 protest IMs were coded in terms of subtype I and subtype II. The coding procedure required data analysis by two raters (first and second authors), who independently coded $100 \%$ of reflection and protest IMs in the 105 EFT sessions. These two raters who coded the reflection and protest IMs according to their subtypes were the same who, in the previous study, coded all these six dyads according to IMCS (Mendes et al., 2010). So, these two raters already had a thorough knowledge of each case.

\section{Results}

\section{Are Reflections and Protest IMs Subtypes Present and Reliably Identified in the six EFT cases?}

All reflection and protest IMs were coded according to the criteria for the subtypes referred to above. Of 
the reflection and protest IMs, $43.5 \%$ were identified as subtype I and $56.5 \%$ were coded as subtype II.

As a measure of agreement on the reflection and protest IMs subtypes coding we used Cohen's Kappa, which in this sample was of .83, showing a strong agreement between judges (Hill \& Lambert, 2004). Thus, as in Lisa's case, reflection and protest IMs subtypes can be reliably identified in EFT sample.

\section{Are Reflection and Protest Subtype II More Typical of Good Outcome Cases in EFT?}

This question was addressed by carrying out a MannWhitney $U$ test given the number of participants in each group $(n=3)$. Clients from the good outcome group were found to have significantly more reflection subtype II $(U=-5.27, p<.001)$ and protest subtype II $(U=-5.61, p<.001)$ IMs than those from the poor outcome group, considering the overall therapeutic process. There were no significant differences between good and poor outcome groups in subtype I of both reflection $(U=-1.37, p=.17)$ and protest $(U=-1.23, p=.22)$ IMs (Figure 2 ).

\section{What is the Evolution of these Subtypes Throughout Therapy, in Good and Poor Outcome Cases in EFT?}

We have considered a non-parametric smoother to summarize the trend of the response variable as a function of treatment session. The black solid line in the plot represents the non-parametric smooth spline of the observed data (Keele, 2008) with respective $95 \%$ confidence intervals, within each outcome group. The advantage of such a smoother is that we do not have to impose any rigid form for such functions. The non-parametric smoothing spline emerges as a solution to an optimization problem, of minimizing simultaneously the residual sum of squares and the second derivative of such a function (Hastie \& Tibshirani, 1990).

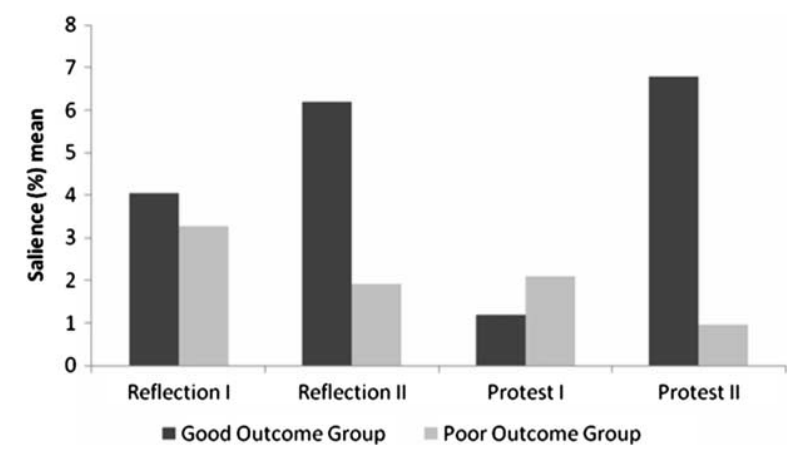

Figure 2. Reflection and protest innovative moments subtypes I and II in good and poor outcome groups.
Although both subtypes of reflection and protest IMs emerge since the beginning of therapy, in good and poor outcome groups, they reveal different evolution patterns. Reflection IMs subtype I present a decreasing path which is similar in good and poor outcome groups (Figure 3). This trend is consistent with the absence of significant differences previously presented. Reflection IMs subtype II demonstrates an increasing trend both in good and poor outcome groups, being clearly higher in the good outcome group (Figure 4), which, once again, is consistent with the results from the previously presented Mann-Whitney $U$ test.

Protest IMs subtype I are very similar in their path in poor and good outcome cases, being stable during treatment (Figure 5). The same does not occur with protest IMs subtype II, exhibiting very different paths in good and poor outcome cases, a difference which is again consistent with the statistical differences between the groups. This IMs subtype is almost absent in the poor outcome group throughout the therapeutic process whereas, in the good outcome group, it shows a progressive line until mid therapy decreasing towards termination (Figure 6).

\section{Discussion}

These results clearly suggest that the subtypes first found in the analysis of the case of Lisa (Gonçalves, Mendes, Ribeiro, et al., 2010) also occurred in other EFT cases, being reliably identified and coded in the transcripts. Moreover, significant differences occurred between good and poor outcome groups in both subtypes II of reflection and protest IMs, but not on subtypes I. This means that, despite the absence of quantitative differences between good and poor outcome cases on overall reflection and protest IMs found in previous studies (Matos et al., 2009; Mendes et al., 2010), if we take the subtypes into account, clear differences emerge. Curiously, the differences between outcome groups occur only in subtypes II (higher in the good outcome group), that is, in the more developed subtypes. Thus, both good and poor outcome clients seem able to elaborate reflection and protest IMs of subtype I (creating distance from the problem or problem-oriented positions), but good outcome cases seem to elaborate more (or more extensively) subtypes II (centered on change or emergence of self-empowerment).

The evolution trends of reflection and protest IMs subtypes I and II provided by the non-parametric smooth spline allow us to have a picture of their developmental trend throughout therapy. Taking the whole sample into account, reflection IM subtype I decreases during treatment, while subtype II increases. Subtype I is centered on understanding 

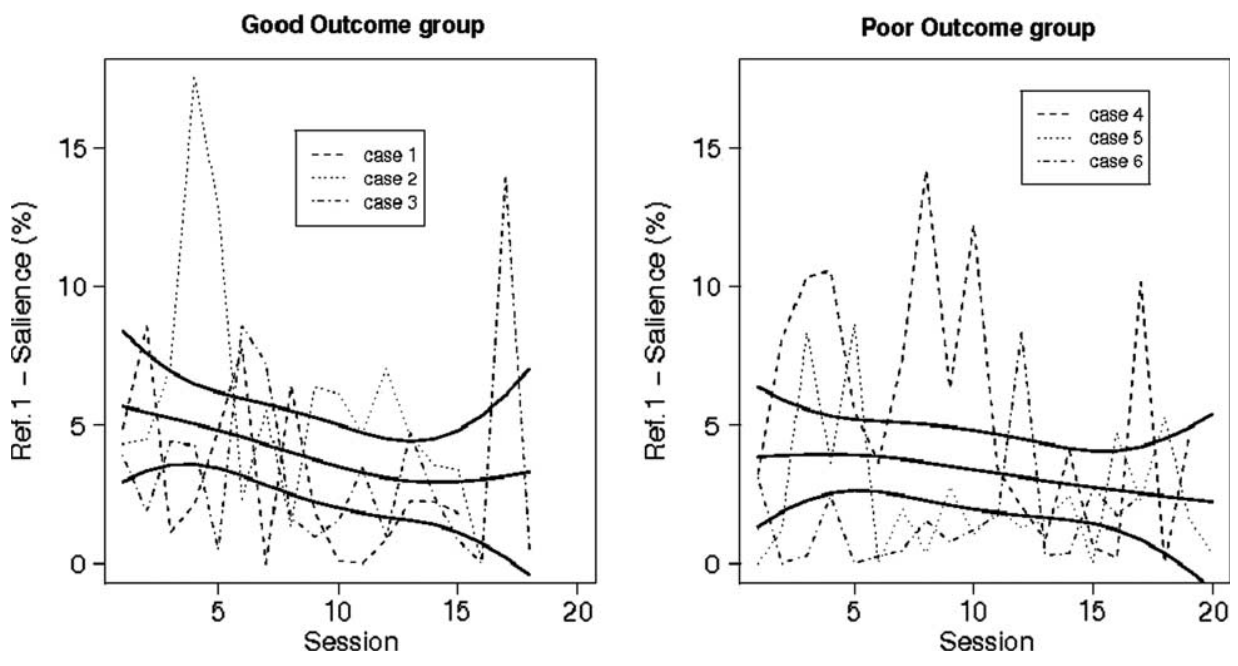

Figure 3. Reflection innovative moments subtype I development throughout therapy in good and poor outcome groups.

the problem, its consequences and effects in the client's life, helping the client to make sense of the emotional experience and the needs these emotions are expressing (Greenberg \& Watson, 2006). As the client progresses in therapy, reflection subtype II increases its presence, addressing new meanings centered on change. This includes, for instance, elaboration on how change is occurring, which strategies are being implemented, emergent selfpositions and new feelings when adopting this new way of experiencing the self. The increasing pattern of reflection subtype II is much more pronounced in the good outcome group than in the poor outcome one. Moreover, this difference is reinforced by the test of differences that shows that subtype II is significantly higher in good outcome cases. So, we could speculate that as reflection subtype I decreases it is substituted in good outcome cases by reflection subtype II, a more elaborated subtype, as we claimed above.

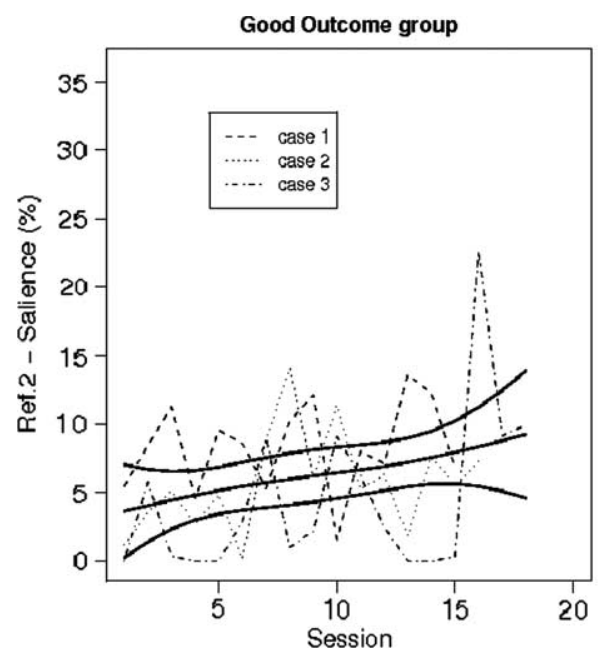

Protest IMs have a curious trend. Subtype I is relatively stable in both outcome groups. Subtype II is also considerably stable in poor outcome cases. The shape of good outcome cases is clearly distinct, having a U-inverted trend. Moreover, as with reflection IMs, there are only differences between groups in subtype II but not in subtype I. This suggests that an important difference between good and poor outcome cases is the difficulty in the last group to change from a focus on others (subtype I) to a focus on the needs of the self (subtype II). It is curious that protest subtype II does not have an increasing trend throughout treatment like reflection subtype II, suggesting that in good outcome cases the affirmation of one's needs, present in subtype II, decreases after the midpoint of therapy. The decreasing line of protest subtype II in the middle of the treatment is apparently coincident, in time, with the increasing of reconceptualization IMs in the good outcome group (Mendes et al., 2010) and we hypothesize that the

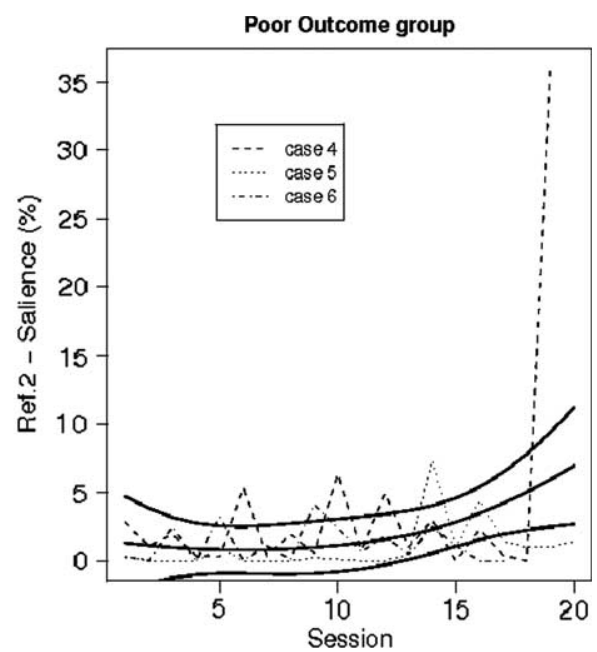

Figure 4. Reflection innovative moments subtype II development throughout therapy in good and poor outcome groups. 

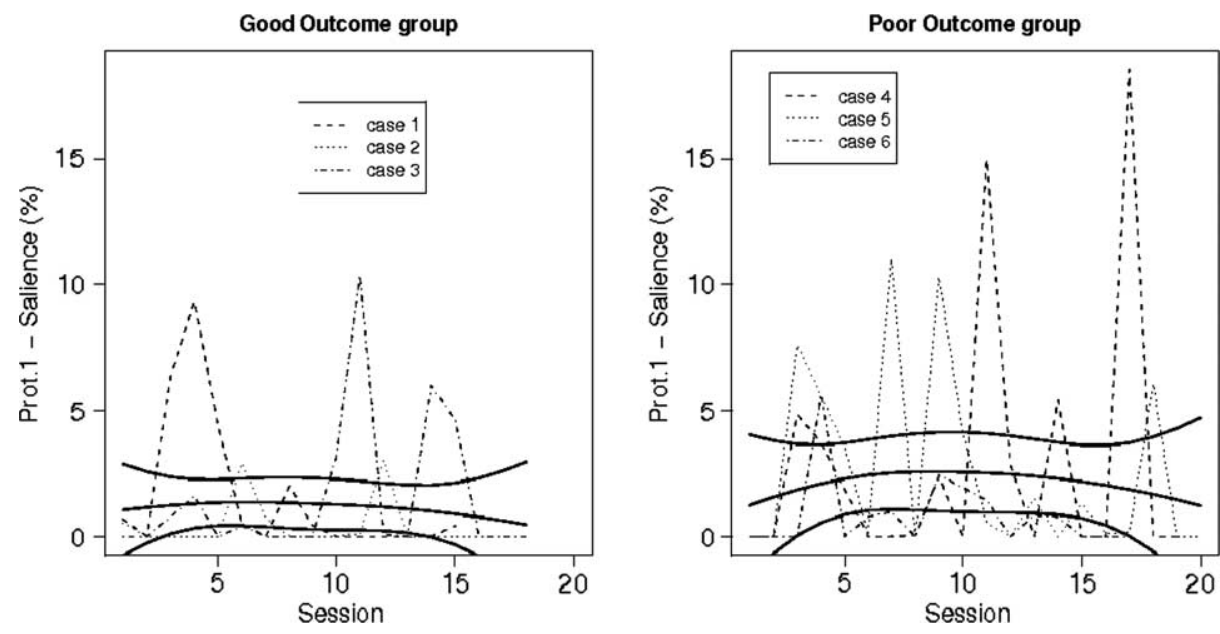

Figure 5. Protest innovative moments subtypes I development throughout therapy in good and poor outcome groups.

clients' elaboration of positions of empowerment, which are embedded in subtype II of protest IMs, may after the midpoint of treatment be involved in the elaboration of reconceptualization. The new selfpositions which emerge in the form of protest IM subtype II may serve as scaffolding for the development of new views of self needed for reconceptualization IMs to emerge.

These results are also congruent with the assumptions of EFT. Therapeutic interventions, like twochair and empty-chair dialogues, demonstrate a shift of core clients themes into new and more differentiated understandings of their problems and their views of the self. As Greenberg (2002) pointed out, the evocation and exploration of the personal meaning of these emotional experiences are related to constructive change in psychotherapy. In EFT, through the therapeutic chair work, clients are stimulated to give voice to another position that involves the voice of their self needs and rights. In good outcome cases, this position of entitlement and empowerment is elaborated in the form of reflection and protest subtypes II and most likely later integrated in reconceptualization IMs. In poor outcome cases clients seem to stay stuck (subtype I), probably as they resist deeply experiencing their emotions, not allowing the voice of the experiencing self to stand up for him or herself (subtypes II). This maintenance of the emotionally distressful experience may constitute an impediment to progress in therapy. When stuck, clients cannot develop the emotional awareness and the "reflective awareness or metacognition [that] is a fundamental skill required for successful psychotherapy" (Greenberg \& Watson, 2006, p. 83). Moreover, Greenberg, Auszra and Herrmann (2007) suggest that clients also need to take responsibility for their emotional experiences instead of blaming others for them (more akin to protest subtype I) and assuming this responsibility facilitates the view of themselves as agents of their own self-change process (subtypes II of reflection and protest IMs, and later on reconceptualization
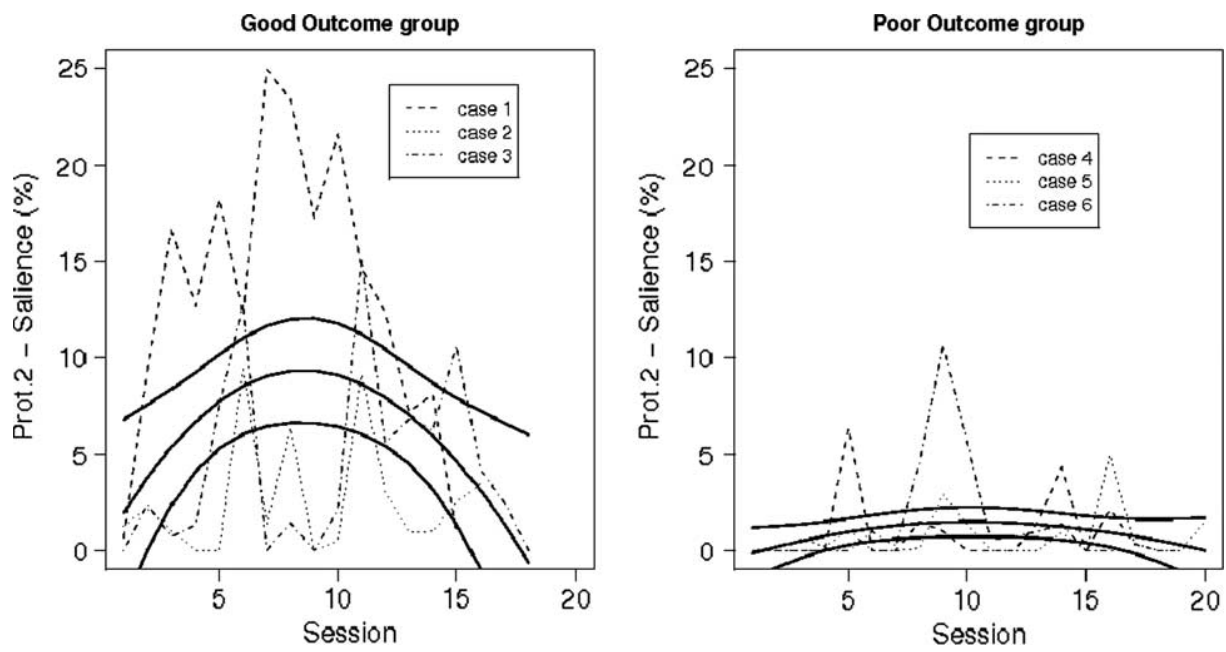

Figure 6. Protest innovative moments subtypes II development throughout therapy in good and poor outcome groups. 
IMs). To sum up, if subtypes I, which constitute the first steps in the process of change, are not expanded and further elaborated, resulting in reflection and protest subtypes II, they probably do not lead toward self-transformation, as occurs in good outcome cases.

Other models of change in psychotherapy have emphasized developmental changes in the treatment process. For instance, the transtheoretical model of change from Prochaska and Norcross (2001) contemplates change as a process which unfolds over time involving the progress through five stages (precontemplation, contemplation, preparation, action, and maintenance), each of them representing different processes of change. If we apply this model of change (Prochaska \& Norcross, 2001) to our findings, we would speculate that subtypes I represent IMs situated in the contemplation stage (awareness of the problem), and subtypes II would take place in later stages, like preparation (intention to take action and the report of small behavioral changes) or action (modification of behavior in order to overcome the problem). Clearly subtype I- either reflection or protest - is much more centered in the understanding of the problem, which is equivalent to Prochaska and Norcross's contemplation stage. Subtype II of reflection and protest implies that the client is much more proactive about the problem, and probably has started to change the problem, which is clearly compatible with later stages of the transtheoretical model.

Another model of change in psychotherapy which suggests that change occurs along a continuum of levels is the assimilation model from Stiles (2006). This model could further help us understand in future studies the differences between subtype I and II of reflection and protest IMs. The assimilation of problematic experiences perspective conceptualizes people as made of multiple internal voices, and suggests that the progress in therapy is associated with the integration of voices - the voice of an unwanted problematic experience in a dominant community of voices (Honos-Webb \& Stiles, 1998; Osatuke \& Stiles, 2006). The sequence through which this integration is achieved is formulated in the eight stages of the assimilation of problematic experiences scale (APES). According to this model, we would hypothesize that subtype I (reflection and protest) would be equivalent to APES level 2 (vague awareness/emergence - the client begins to be more aware of the non-dominant voice). We may also consider that sometimes subtype I may achieve level 3 (problem statement/clarification - the client is able to have a clear statement of the problem), specifically when clients elaborate new formulations about the problem and are able to articulate the consequences of it in his or her life. Subtype II, of both reflection and protest IMs, is probably related to stages 4 (understanding/insight) and 5 (application/working through) since it entails clients' moving through a clear understanding of the problematic experience with mixed affect to a positive affect and problemsolving efforts. In summary, subtypes I are probably less developed (contemplation in the transtheoretical model of behavior change or stage 2 or 3 in APES), than subtypes II (preparation and higher in the transtheoretical model or stage 4 and higher in APES).

Succinctly, these results seem congruent with the EFT theory (Greenberg \& Watson, 2006) and with developmental models of therapy, like the transtheoretical model of change (Prochaska \& Norcross, 2001) or the assimilation model (Stiles, 2006), that conceive therapy as a process of increasing complexity. At this point, it is not clear if these patterns are exclusive of EFT samples or if they reflect common processes of change present in several models of brief psychotherapy, similar to other findings that resulted from the application of IMCS (Gonçalves, Santos, et al., 2010).

\section{Limitations}

The size of the analyzed sample of the present study makes its conclusions limited and exploratory and obviously does not allow testing some of our speculations (e.g., protest II as a precursor of reconceptualization IMs). Another limitation was the knowledge that the coders had about the status of the cases, in terms of good or poor outcome, since they were the ones who had done the previous coding with the IMs in the study of Mendes and colleagues (2010).

Although this study helped further the development of the IMCS, allowing us to understand the role of two of the most common IMs - reflection and protest - we can only consider these new findings in the light of the specific therapeutic model in which they emerge-EFT. More research is needed to see if the same subtypes emerge in other forms of therapy and if they have the same role in the construction of a preferred self-narrative.

At this point we do not know how the concept of IM could be applied to more severe psychopathology. For instance, Lysaker and Lysaker (2006) described the treatment of a highly disorganized self-narrative of a patient with schizophrenia (see Dimaggio, 2006, for a review of narrative disruptions). The application of the IMs' concept and tools of research to these forms of narrative disruptions will certainly pose specific challenges and difficulties. So far we have never applied this research method to 
very disturbed patients, like the ones suffering from psychosis or severe personality disorders. We suspect that if a problematic self-narrative is identified at the onset of therapy IMs can also be identified, even in these more disturbed patients.

Finally, this method implies the identification of the problematic narrative at the onset of therapy. The two judges consensually define the problematic dimensions which comprised each client's problematic self-narrative (as close as possible to the client's discourse). These problematic dimensions coincide with the therapeutic targets that the therapist and the client are addressing. This is clearly a limitation of the method, since we do not use any formal way of coding the problematic self-narrative. Existing formal tools (like the CCRT; see Luborsky, 1997) could technically be used, but this method is already very demanding and time-consuming; thus, so far we have not used any formal means of assessment of the previous problematic narrative.

\section{Acknowledgements}

The authors are grateful to Carla Cunha for her comments on the first draft of this article.

This article was supported by the Portuguese Foundation for Science and Technology (FCT), by the Research Grant PTDC/PSI/72846/2006 (Narrative Processes in Psychotherapy, 2007-2010), and the PhD Grants SFRH/BD/29804/2006 and SFRH/ $46189 / 2008$.

\section{References}

Alves, D., Mendes, I., Neimeyer, R., \& Gonçalves, M. (2011). Innovative moments and change in constructivist grief psychotherapy: The case of Cara. Manuscript in preparation.

Angus, L., Goldman, R., \& Mergenthaler, E. (2008). Introduction. One case, multiple measures: An intensive case-analytic approach to understand client change processes in evidencebased, emotion-focused therapy of depression. Psychotherapy Research, 18, 629-633.

Angus, L., \& McLeod, J. (Eds.). (2004). The handbook of narrative psychotherapy: Practice, theory and research. London: Sage.

Beck, A.T., Steer, R.A., \& Garbin, M.G. (1988). Psychometric properties of the Beck Depression Inventory: Twenty-five years of evaluation. Clinical Psychology Review, 8, 77-100.

Beck, A.T., Ward, C.H., Mendelson, M., Mock, J., \& Erbaugh, J. (1961). An inventory for measuring depression. Archives of General Psychiatry, 4, 561-571.

Brinegar, M.G., Salvi, L.M., \& Stiles, W.B. (2008). The case of Lisa and the assimilation model: The interrelatedness of problematic voices. Psychotherapy Research, 18, 657-666.

Bruner, J. (1986). Actual minds, possible worlds. Cambridge, MA: Harvard University Press.

Carcione, A., Dimaggio, G., Fiore, D., Nicolò, G., Procacci, M., Semerari, A., \& Pedone, R. (2008). An intensive case analysis of client metacognition in a good outcome psychotherapy: Lisa's case. Psychotherapy Research, 18, 667-676.
Dimaggio, G. (2006). Disorganized narratives in clinical practice. fournal of Constructivist Psychology, 19, 103-108.

Gendlin, E.T. (1981). Focusing (2nd ed). New York: Bantam Books.

Gonçalves, M.M., Matos, M., \& Santos, A. (2009). Narrative therapy and the nature of "innovative moments" in the construction of change. Fournal of Constructivist Psychology, 22, 1-23.

Gonçalves, M.M., Mendes, I., Cruz, G., Ribeiro, A., Angus, L., \& Greenberg, L. (2011). Innovative moments and change in client-centered therapy. Manuscript in preparation.

Gonçalves, M.M., Mendes, I., Ribeiro, A., Angus, L., \& Greenberg, L. (2010). Innovative moments and change in emotional focused therapy: The case of Lisa. fournal of Constructivist Psychology, 23, 1-28.

Gonçalves, M.M., Ribeiro, A.P., Conde, T., Matos, M, Santos, A., Martins, C., \& Stiles, W.B. (2011). The role of mutual infeeding in maintaining problematic self-narratives: Exploring one path to therapeutic failure. Psychotherapy Research, 21, $27-40$.

Gonçalves, M.M., Ribeiro, A., Mendes, I., Matos, M., \& Santos, A. (in press). Tracking novelties in psychotherapy process research: The Innovative Moments Coding System. Psychotherapy Research.

Gonçalves, M.M., Santos, A., Matos, M., Salgado, J., Mendes, I., Ribeiro, A., Cunha, C., \& Gonçalves, J. (2010). Innovations in psychotherapy: Tracking the narrative construction of change. In J.D. Raskin, S.K. Bridges \& R. Neimeyer (Eds.), Studies in meaning 4: Constructivist perspectives on theory, practice, and social justice (pp. 29-64). New York: Pace University Press.

Greenberg, L.S. (2002). Emotion-focused therapy: Coaching clients to work through their feelings. Washington, DC: American Psychological Association.

Greenberg, L.S. (2008). The case of Lisa: An integration and reaction to the process analyses. Psychotherapy Research, 18, $677-682$.

Greenberg, L.S., Auszra, L., \& Herrmann, I.R. (2007). The relationship among emotional productivity, emotional arousal and outcome in experiential therapy of depression. Psychotherapy Research, 17, 482-493.

Greenberg, L.S., Rice, L.N., \& Elliott, R. (1993). Facilitating emotional change: The moment-by-moment process. New York: The Guilford Press.

Greenberg, L.S., \& Watson, J. (1998). Experiential therapy of depression: Differential effects of client-centred relationship conditions and process interventions. Psychotherapy Research, 8, 210-224.

Greenberg, L.S., \& Watson, J.C. (2006). Emotion-focused therapy for depression. Washington DC: American Psychological Association.

Hastie, T., \& Tibshirani, R. (1990). Generalized additive models, Volume 43 of Monographs on statistics and applied probability. London: Chapman \& Hall.

Hermans, H.J.M. (2003). The construction and reconstruction of a dialogical self. Fournal of Constructivist Psychology, 16, 89-130.

Hill, C.E., \& Lambert, M.J. (2004). Methodological issues in studying psychotherapy processes and outcomes. In M.J. Lambert (Ed.), Bergin and Garfield's handbook of psychotherapy and behavior change (5th ed., pp. 84-135). New York: Wiley.

Honos-Webb, L., \& Stiles, W.B. (1998). Reformulation of assimilation analysis in terms of voices. Psychotherapy Research, 7, 23-33.

Honos-Webb, L., Stiles, W.B., Greenberg, L.S., \& Goldman, R. (1998). Assimilation analysis of Process-Experiential Psychotherapy: A comparison of two cases. Psychotherapy Research, 8, 264-286.

Horvath, A., \& Greenberg, L. (1989). Development and validation of the Working Alliance Inventory. Fournal of Counselling psychology, 36, 2, 223-233. 
Jacobson, N.S., \& Truax, P. (1991). Clinical significance: A statistical approach to defining meaningful change in psychotherapy research. Fournal of Consulting and Clinical Psychology, 59, 12-19.

Keele, L. (2008). Semiparametric regression for the social sciences. New York: John Wiley and Sons.

Lepper, G., \& Mergenthaler, E. (2008). Observing therapeutic interaction in the "Lisa" case. Psychotherapy Research, 18, 634-644.

Lysaker, P.H., \& Lysaker, J.T. (2006). A typology of narrative impoverishment in schizophrenia: Implications for understanding the processes of establishing and sustaining dialogue in individual psychotherapy. Counselling Psychology Quarterly, 19, $57-68$.

Luborsky, L. (1997). The core conflictual relationship theme: A basic case formulation method. In T.D. Eels (Ed.), Handbook of psychotherapy case formulation (pp. 58-83). New York: Guilford.

McAdams, D.P. (1993). The stories we live by: Personal myths and the making of the self. New York: William Morrow.

Matos, M., Santos, A., Gonçalves, M.M., \& Martins, C. (2009). Innovative moments and change in narrative therapy. Psychotherapy Research, 19, 68-80.

McGlinchey, J.B., Atkins, D.C., \& Jacobson, N.S. (2002). Clinical significance methods: Which one to use and how useful are they? Behavior Therapy, 33, 529-550.

Mendes, I., Ribeiro, A., Angus, L., Greenberg, L., Sousa, I., \& Gonçalves, M. (2010). Narrative change in emotion-focused therapy: How is change constructed through the lens of the Innovative Moments Coding System? Psychotherapy Research, 20, 692-701.

Neimeyer, R.A., Herrero, O., \& Botella, L. (2006). Chaos to coherence: Psychotherapeutic integration of traumatic loss. Fournal of Constructivist Psychology, 19, 127-145.

Nicolò, G., Dimaggio, G., Procacci, M., Semerari, A., Carcione, A., \& Pedone, R. (2008). How states of mind change in psychotherapy: An intensive case analysis of Lisa's case using the Grid of Problematic States. Psychotherapy Research, 18, 645-656.
Osatuke, K., \& Stiles, W. (2006). Problematic internal voices in clients with borderline features: An elaboration of the assimilation model. Fournal of Constructivist Psychology, 19, 287-319.

Polkinghorne, D.E. (1988). Narrative knowing and the human sciences. Albany, NY: State University of New York Press.

Prochaska, J.O., \& Norcross, J. (2001). Stages of change. Psychotherapy, 38, 443-448.

Ribeiro, A.P., Gonçalves, M.M., \& Ribeiro, E. (2009). Processos narrativos de mudança em psicoterapia: Estudo de um caso de sucesso de terapia constructivista [Narrative change processes in psychotherapy: A case-study of successful constructivist therapy]. Psychologica, 50, 181-203.

Santos, A., Gonçalves, M., Matos, M., \& Salvatore, S. (2009). Innovative moments and change pathways: A good outcome case of narrative therapy. Psychology and Psychotherapy: Theory, Research and Practice, 82, 449-466.

Santos, A., Gonçalves, M.M., \& Matos, M. (in press). Innovative moments and poor-outcome in narrative therapy. Counselling and Psychotherapy Research.

Sarbin, T.R. (1986). The narrative and the root metaphor for psychology. In T.R. Sarbin (Ed.), Narrative psychology: The storied nature of human conduct (pp. 3-21). New York: Praeger.

Semerari, A., Carcione, A., Dimaggio, G., Faclone, M., Nicolò, G., Procacci, M., et al. (2003). The evaluation of metacognitive function in psychotherapy: The metacognitive assessment scale and its applications. Clinical Psychology and Psychotherapy, 10, 238-261.

Semerari, A., Carcione, A., Dimaggio, G., Nicolò, G., \& Procacci, M. (2007). Understanding minds: Different Psychotherapy Research, 17, 106-119.

Stiles, W.B. (2006). Assimilation and the process outcome: Introduction to a special issue. Psychotherapy Research, 16, 389-392.

The Case of Lisa [Special Section] (2008). Psychotherapy Research, 18(6).

White, M., \& Epston, D. (1990). Narrative means to therapeutic ends. New York: Norton. 